\title{
Hacia una revaloración ontológica del tridimensionalismo iusfilosófico como respuesta a los grandes retos del derecho actual. Estado del arte*
}

\author{
Jorge Humberto Gartner López* \\ Candidato a Magister en Derecho \\ Universidad Sergio Arboleda
}

\begin{abstract}
Resumen
Una breve mirada sobre el panorama de la actual filosofía del Derecho postpositivista, caracterizada por el reconocimiento de una estructura trielemental (fáctica-axiológica-normativa), con el propósito de entender la aparición del Tridimensionalismo Iusfilosófico Específico y sus posibilidades como teoría integradora permitirá, junto con la lectura de autores comprometidos con una filosofía postmetafísica y del giro lingüístico, el rescate del Ser como eje del Derecho, y la fundamentación de una filosofía del Derecho capaz de afrontar los retos planteados por los nuevos avances científicos y tecnológicos en materia de bioética y medios masivos de comunicación e información.
\end{abstract}

\section{Palabras clave}

Recuperación del Ser, Tridimensionalismo Iusfilosófico, Derecho natural, ontología jurídica, axiología jurídica, lógica jurídica, dialecticidad, integrativismo, desontologización, nuevas tecnologías, bioética.

\begin{abstract}
A brief glance at the panorama of actual post-positivist philosophy of Law, characterized by the acknowledgement of a three-elementary structure (factical-axiological-normative), with the purpose of understanding the appearance of Specific Jusphilosophical Tridimensionalism and its possibilities as an integrative theory will allow, with the reading of authors commited to a post-metaphysical and linguistic turn philosophy, the rescue of the Being as the axis of Law, and the fundamentals for a philosophy of Law, able to confront the challenges established by the new scientific and technological advances in matters of bioethics and communication and information mass-media.
\end{abstract}

Key words

Retrieve of Being, Jusfilosofical Tridimensionalism, Natural law, Juridical ontology, Juridical axiology, Juridical logics, Dialecticity, Integrativism, Disontologitation, New technologies, Bioethics.

Fecha de recepción del artículo: 30 de noviembre de 2007

Fecha de Aceptación del artículo: 15 de diciembre de 2007

${ }^{*}$ El presente estado del arte corresponde al desarrollo del proyecto de tesis de Maestría que lleva el mismo título, dirigido por la profesora Liliana Beatriz Irizar, docente investigadora de la Escuela de Filosofía de la Universidad Sergio Arboleda y directora del grupo de investigación LUMEN.

${ }^{* *}$ Abogado; candidato a la Maestría en Derecho por la Universidad Sergio Arboleda. Actualmente se desempeña como Juez Administrativo en la ciudad de Pereira, (Risaralda), y como docente de la Universidad Libre seccional Pereira donde dicta los cursos de Filosofía del Derecho, Ética y Lógica Jurídica. 


\section{Problema de investigación y método}

¿Cómo establecer las bases filosóficas necesarias para la reconstrucción de un Derecho acorde con las cuestiones actuales que enfrenta el mismo, derivadas del desarrollo de nuevas tecnologías y de la revolución mediática, desde la revaloración que propone el tridimensionalismo Iusfilosófico, esto es, ontología, lógica y estimativa jurídicas, integradas más allá de la forma tradicional de entender la filosofía, la Iusfilosofía y por ende, más allá de la forma tradicional de asumir la construcción del conocimiento?

Dadas las características del tema de investigación, siguiendo la clasificación actual de las nuevas perspectivas iusfilosóficas (Robles, 2003, pp. 179-199), se acudirá a una estrategia metodológica integrativa de tipo constructivista, la cual conjuga: la teoría formal de la ciencia (puesto que es necesario acudir a todo aquello atinente a las normas jurídicas, la jurisprudencia y la doctrina, al igual que a las distintas áreas del conocimiento del Derecho público y privado; es lo que se denomina también investigación jurídica); el análisis lingüistico y la hermenéutica. En el tema propuesto existe, en efecto, una relación entre el Derecho y otras disciplinas del conocimiento; asimismo, con fenómenos sociales, políticos y filosóficos que deben ser interpretados de manera contextual y partiendo de la importancia capital que tiene el fenómeno del lenguaje como forma de ser de los humanos en el mundo. Esta situación justifica las dos últimas metodologías señaladas.

Primeramente, se intentará la reconstrucción histórica del problema del Derecho a lo largo del pensamiento occidental, y de cómo se operó un progresivo recorte de mundo, una fragmentación en la consideración del Ser como fundamento de la reflexión filosófica, que degeneró en la aparición del positivismo. Posteriormente, se analizará el tránsito hacia una postura trielemental como respuesta y superación del positivismo. A partir de allí se intentará una revisión crítica de la Teoría Tridimensional del
Derecho desde una postura ontológica, en miras de hacer un aporte al estudio de la problemática actual del Derecho, en materia de bioética y medios de comunicación e información, temática en la cual las investigaciones de Jesús Ballesteros serán fundamentales.

La tesis de que el Derecho se fundamenta en la Filosofía parece cobrar cada día mayor vigencia, por lo menos desde el renacer del Derecho natural de principios del siglo XX con teóricos como Del Vecchio, Geny y Krabbe (Friedrich, 1997). Pero la forma en que entendemos los elementos constitutivos de una filosofía del Derecho, cambia según la doctrina, aunque actualmente se logre esclarecer como común el estudio de una esencia ontológica, una estructura lógica, y una axiología o estimativa. (Mantilla Pineda, 2003). Dicho estudio tripartito se ha convertido en un problema, dada la dificultad fundamental de pretender subordinar a uno solo de estos elementos constitutivos los otros dos. Usualmente, termina siendo lo axiológico o lo estimativo lo que cobra mayor relevancia, cuando no, en el más desafortunado de los casos, la esencia lógica, esto es, el sistema normativo, en detrimento de las otras dos. Lo que aquí entra en juego es, entonces, la búsqueda de alternativas que permitan esclarecer la forma en que, desde una gradación epistemológica, el Derecho se nutre desde estas tres ramas en un ejercicio integrativista; alternativas que contribuyan a abordar adecuadamente realidades culturales problemáticas actuales como lo son las que pertenecen al campo de la bioética y de los medios masivos de comunicación e información.

Por todo lo anterior, se propone una revaloración de la teoría del Tridimensionalismo Iusfilosófico que permita trascender esquemas obsoletos y redimensionar el Derecho, haciendo posible dar fundamento filosófico a la reflexión sobre sus cuestiones actuales; cuestiones que tienen que ver con los nuevos avances científicos y tecnológicos y sus repercusiones en la bioética, así como en todo el fenómeno de los medios de comunicación y/o información (usos, contenido, 
responsabilidad, influencia). En estas cuestiones se cifra el carácter de las relaciones que los humanos entablaremos en el futuro y sobre las cuales debe interesarse el Derecho como reflexión sobre el mundo de la vida humana. Es aquí donde el enfoque actual del Tridimensionalismo, entra a jugar un papel decisivo para avocarse el estudio, análisis e investigación de los grandes temas y retos del Derecho actual. Sin dejar de lado la dimensión lógico-jurídica, se pretende ahondar en las otras dos dimensiones, poco exploradas, de la disciplina Iusfilosófica (estimativa o axiología y ontología jurídicas), siempre tras el objetivo de aportar al soporte filosófico necesario para afrontar las cuestiones actuales del Derecho.

Tiene gran relevancia en este aspecto la posición filosófica predominante en la mayoría de pensadores contemporáneos, la llamada filosofía de la sospecha, que abarca un grupo heterogéneo de filósofos, ubicables en la línea de la Filosofía del Lenguaje, quienes comparten puntos comunes como el de encontrar una relación íntima entre filosofía y lenguaje, el adoptar una actitud cautelosa hacia la metafísica y una actitud crítica hacia el saber científico positivo, además del reconocimiento implícito o expreso de que es necesaria una reflexión seria sobre las bases de la filosofía tradicional y su validez.

En este sentido, aparecen como ejes problemáticos:

- ¿Existe una esencia o ser del Derecho, es decir, una naturaleza ontológica? Si es así ¿cuál es su incidencia en el redimensionamiento iusfilosófico con miras al estudio, análisis y regulación de las cuestiones actuales del Derecho?

- ¿Cómo puede abordarse el estudio de las cuestiones actuales de la ciencia jurídica desde la perspectiva de la estimativa o axiología jurídicas como partes vitales de la Filosofía del Derecho?

\section{Introducción}

E1 mundo actual enfrenta procesos revolucionarios como el desarrollo de nuevas tecnologías, la globalización y la complejidad de los medios de información y comunicación, que en cierta medida modifican la forma de entender las diversas facetas del Derecho. Cada vez más, el Derecho positivo encara situaciones ante las cuales se manifiesta insuficiente, máxime cuando éstas tienen que ver con una modificación de los horizontes de realidad y de sentido de los humanos. Eventos como la manipulación del genoma humano y la subsiguiente posibilidad de la clonación, así como la abrumadora revolución mediática, resultan ejemplos adecuados, en la medida que la resolución de sus conflictos tiene más que ver con la filosofía del Derecho como disciplina original que con los ordenamientos jurídicos particulares de cada Estado. Cuando se cae en la cuenta de que la iusfilosofía se ha estancado con la hegemonía de sistemas como el de la lógica jurídica, aparece imprescindible la necesidad de reconstruir un discurso más adecuado a la mecánica del mundo actual; un discurso que provenga de una reflexión juiciosa y concienzuda sobre las bases ontológicas y axiológicas, además de las lógicas, del Derecho.

Esta necesidad de reflexión iusfilosófica es la que motiva la realización del presente proyecto en el que, a partir de la revisión de la Teoría Tridimensional del Derecho, inaugurada por Miguel Reale y continuada por Carlos Fernández Sessarego, se pretende dar un fundamento para afrontar los nuevos avances científicos y tecnológicos en materia de bioética y medios masivos de comunicación y sus repercusiones en las cuestiones actuales del Derecho, siempre procurando la defensa de una postura ontologista. Ésta queda sustentada en trabajos de diferentes filósofos y teóricos del Derecho, con base en los cuales se sostiene que, si existe una crisis en los ideales humanos agravada desde la llegada de la modernidad, es precisamente debido a un sistemático proceso de abandono del Ser como pilar de toda reflexión filosófica. Este proceso se 
inaugura en la modernidad, concretamente a partir de Descartes, y tiene su última expresión en el positivismo científico. Tales aseveraciones son el resultado de la indagación histórica realizada a partir del trabajo de diferentes hermeneutas postpositivistas comprometidos generalmente con la filosofía del giro lingüístico, la cual resulta vital a la hora de pensar muchos de los fenómenos humanos, entre ellos el Derecho.

La materia de la que está hecha la realidad es la palabra. Entender el mundo es apalabrarlo y así darle sentido. El Derecho permite que los humanos convivamos en condiciones de dignidad, justicia y equidad a partir de la mediación de esa palabra. Hacer que las ciencias del Derecho estén más acorde con esa asignación de sentido, con ese apalabrar el mundo, es acercarlas más a la consecución de sus ideales. Por ello, es necesario que una verdadera filosofía del Derecho dé cuenta de las posibilidades humanas, tanto de las preexistentes como de las más recientes y aun de las postreras, visualizando y previniendo aquellas que, debido al inmenso poder que otorgan el conocimiento científico y el manejo de los medios, impliquen un peligro para la continuidad de la convivencia y de la consideración del Ser como fin en sí mismo y no como simple medio para la consecución de la riqueza y el poder. De allí que el Derecho, como disciplina llamada a convertirse en custodia del Ser humano, deba fundamentarse desde esta misma dimensión ontológica.

La presente investigación pretende indagar sobre las posibilidades de una revaloración de la Teoría Tridimensional del Derecho, concepción de avanzada en el pensamiento iusfilosófico contemporáneo, tomándola como postura fundamental para reflexionar sobre las complejidades que debe afrontar un Derecho que se quiera desarrollar de forma consecuente con los avances científicos y tecnológicos de la actualidad. El enfoque actual del Tridimensionalismo, entra a jugar un papel decisivo en el estudio, análisis e investigación de los grandes temas y retos del Derecho actual. Se pretende ahondar en las tres dimensiones de la disciplina Iusfilosófica (ontología, estimativa o axiología y lógica jurídicas) de manera integracionista, siempre tras el objetivo de aportar al soporte filosófico necesario para afrontar las cuestiones actuales del Derecho.

Se pretende, entonces, ofrecer un aporte a los análisis jurisprudenciales desde una perspectiva filosófica, ofreciendo una base para construir un Derecho más acorde con el contexto cultural actual, de suyo, sujeto a constantes y profundos cambios. Para esto será necesario reconstruir el panorama histórico de la filosofía del Derecho hasta llegar al reconocimiento de su naturaleza tripartita o tricotómica (ontológica, axiológica y lógica) con base en autores clásicos como Giorgio del Vecchio, Edgar Bodenheimer, Carl Joachim Friedrich, Luís Recaséns Siches, Benigno Mantilla Pineda y otros relevantes en el tema. Se trata, sin embargo, de autores que, aunque reconocen la importancia de estos tres elementos, no han logrado una verdadera integración satisfactoria (o tridimensional).

Con el ánimo de realizar una critica a lo que ha sido el pensamiento occidental, desde que fue inaugurado por los griegos en la antigüedad clásica hasta la actualidad, serán tenidos en cuenta autores como Julián Serna Arango, y Gregorio Robles, quienes realizan, cada cual desde una posición diferente, una lectura postmetafísica del Derecho en la que se reconoce el problema de la desontologización. Posteriormente se dará valor a las nuevas teorías del Derecho insertas en el Tridimensionalismo desde la visión de autores como José Silva Cueva, Miguel Reale y Carlos Fernández Sessarego. Finalmente, se relacionarán estos conceptos, para revalorar sus postulaciones, con las investigaciones iusfilosóficas de Jesús Ballesteros con miras a afrontar los nuevos avances científicos y tecnológicos y sus repercusiones en del Derecho actual.

José Silva Cueva, jurista peruano, es el autor del primer documento a referenciar aquí: el artículo titulado Visión Tridimensional del 
Derecho (Silva, 2006). Desarrolla allí consideraciones generales sobre la relación FilosofíaDerecho, además de exponer un breve panorama histórico de la Iusfilosofía para finalmente adentrarse en las razones de la aparición de la Teoría Tridimensional del Derecho y hacer una reflexión en torno a la aplicabilidad del Tridimensionalismo y el sentido que el Derecho tiene en la existencia humana. Retomando palabras de Silva (2006):

(..) la historia demuestra que el pensamiento filosófico, $y$ de modo especial el que atañe al derecho en cuanto es conducta compartida, se nutre, a su vez, del hecho histórico, de la indagación empírica, de la realidad, de la vida. Vida es todo lo que hacemos cuando nos damos cuenta de que lo hacemos. Por eso, anota con firmeza Recaséns Siches que 'el derecho se encuentra en el reino de la vida humana, y es obvio que sólo allí puede estar'. Desconocer este nexo interactivo de la filosofía del derecho con el acontecer humano sería incurrir de nuevo en los excesos de la Escuela del Derecho Natural, con filiación en el siglo XVIII, que, saturada de razón, pretendió construir un sistema de verdades jurídicas a base de conceptos absolutos, sin flexibilidad ni matices, como si los infinitos modos de manifestarse la riqueza espiritual de lo humano tendiera a cristalizar en moldes racionales, inmutables y eternos. (p. 1).

Y es aquí y ahora donde es pertinente cuestionarse sobre qué implica esta afirmación, en cuanto al peso que trae consigo en relación con los derechos humanos; más específico el caso, con el derecho a la vida (según la definición de vida de Silva ya citada). Algunas de las cuestiones bioéticas actuales son la inteligencia artificial, la clonación humana, entre otras; cuestiones que modifican el sistema de valores de la sociedad, su comportamiento y su mentalidad. Porque, dentro de este panorama cultural, pueden surgir interrogantes tales como:
¿Es posible hablar de inteligencia artificial? ¿Cuál es el estatus antropológico de, ser posible el caso, un ser humano clonado tan sólo para cumplir ciertas labores de forma inconsciente y que por ello tiene limitaciones mentales? ¿En qué momento de la gestación comienza la vida humana? Es ante situaciones nuevas como éstas donde al Derecho le corresponde entrar a ejercer su función reguladora y orientadora de lo social, pero asumiendo que dichos cambios se suelen presentar de modo inesperado, irrumpiendo y conmocionando el orden social. Las nuevas tecnologías, en efecto, nunca aparecen tras un consenso interindividuos, sino que lo hacen de súbito, producto del conocimiento, necesidades y conveniencia de unos cuantos. Ligado a lo anterior podemos tomar la siguiente apreciación, también de Silva Cueva (2006):

Pero si entendemos el Derecho como lo hacían los juristas medievales, es decir, como modelo de un cierto tipo de pensamiento riguroso, entonces el orden jurídico no es un conjunto de leyes sino más bien un razonamiento, un modo de pensar. Las normas no son sino los materiales de construcción de ese razonamiento, con las cuales se pueden hacer edificaciones bastante diferentes según el plano que se pretenda implantar. (p. 4).

Pero, si al Derecho se lo considera como un tipo de pensamiento riguroso, un modo de pensar basado únicamente en normas positivas previas ¿cómo afrontar avances sobre los cuales no hay precedentes en materia de Derecho, ni hay normas previas? Para cuando una normatividad, al igual que la sociedad en general, se ha adaptado a la aparición de un avance científico o tecnológico y sus repercusiones en la existencia humana, muchas veces la adaptación ya está en obsolescencia, máxime cuando se tomaron normas anteriores descontextualizadas para realizar la reflexión que permitió la adaptación.

El Derecho es consecuencia de diversos procesos en los que resulta difícil dar 
preponderancia a uno, ya al económico, ya al psicológico y/o racional. Desde el aspecto económico, el Derecho se considera resultante de las condiciones materiales de la vida o de los modos de producción y distribución de la riqueza. Pero para algunos, el talante económico es a la vez la consecuencia de tendencias psíquicas (y subjetivas), es decir, sentimientos, necesidades de la naturaleza humana, esquemas particulares de adquisición del conocimiento. En esa medida, el Derecho surgiría bajo criterios (y valoraciones) subjetivos de lo justo (de forma natural), que en ocasiones se deslindan del Derecho Positivo. Aunque el Derecho corresponda al ámbito de la conciencia (ninguna actividad relacionada con el Derecho puede realizarse de forma inconsciente) y pretenda universalizarse en sus fundamentos ideales, muchas veces, las concepciones tanto de Derecho Natural como de Derecho Positivo acordadas en una época específica entran en crisis porque no corresponden con otros espacios $\mathrm{y}$ tiempos determinados en los que eventos y situaciones de ruptura emergen súbitamente. Ahí es cuando se habla de que la ley o Derecho Positivo (de carácter estrictamente lógico) en ese caso coyuntural, sería un mandato arbitrario y descontextualizado y al ser humano no le quedaría más que adaptarse a esta imposición, aun siendo consciente de la obsolescencia o injusticia de las normas o rebelarse contra ellas invocando unos principios superiores. Es por esto que el Derecho debe estar supeditado constantemente a cambios, ya que es necesario asumir posturas críticas y reflexivas a la hora de establecer justicia en atención a la integridad y la dignidad del individuo.

Pero cuando esa complejidad es reducida con base en una hegemonía económica que marca la pauta y se construye inescrupulosamente toda una estrategia para vender un modo de pensamiento e implantarlo como una opinión igual para todos los pueblos a partir de la revolución mediática, como ha expuesto McLuhan ${ }^{1}$, lo que se quiere es brindar a los ciudadanos un confort metafísico, evitarles la molestia de pensar. Aquí están implicados, pues, los fenómenos relacionados con los medios masivos de comunicación e información (mass-media) y su influencia en las cuestiones del Derecho actual.

Se ha comenzado esta relación sobre el estado del arte haciendo mención del artículo de Silva (2006) porque fue a partir de su lectura que se generó el interés por el presente tema de investigación y se visualizó una posible ruta para su realización. Esto es, la revisión histórica de ciertos elementos que han marcado la filosofía occidental y han desembocado en la actual crisis en torno al ser humano y su realidad existencial. Dicha lectura despertó, asimismo, el interés por el llamado giro lingüístico en materia de filosofía.

Pero, estrictamente, lo que Silva realiza es un análisis del Tridimensionalismo Iusfilosófico Específico, teoría formulada expresamente por otros dos autores: Miguel Reale y Carlos Fernández Sessarego. Lo estrictamente relativo al Tridimensionalismo llamado Específico, en contraposición al llamado Genérico o Abstracto, se inaugura con el primero de los autores. Cuando se hace la diferenciación entre el Tridimensionalismo Genérico y el Específico se está hablando de que el primero se relaciona con aquellos teóricos que reconocen en el Derecho una estructura trielemental (hecho, valor y norma), pero que no integran dichos elementos dentro de una relación o sistema coherente. El segundo sería entonces el tridimensionalismo propuesto por Reale en sus fases iniciales como "complejo factico-axiológico-normativo, que identifica una realidad única e indesligable y que es el mundo propio del Derecho" (Silva, 2006, p. 9), y posteriormente desarrollado por Fernández Sessarego.

Para dar una idea al lector de cuál es la posición actual sobre los problemas que entraña la temática del derecho se ha recurrido a la obra Filosofía del derecho del profesor de la Universidad de Antioquia, Benigno Mantilla Pineda. En el libro ya mencionado, Mantilla plasma una cuidadosa descripción de las corrientes del pensamiento jurídico contemporáneo, y entre ellas una hecha perceptible desde 
principios de los cuarenta en América y en los países ibéricos (España y Portugal), denominada Tridimensionalismo Específico y/o Concreto. Allí presenta también el pensamiento de los reformuladores de la Filosofía del Derecho a principios del siglo $\mathrm{XX}$ (con la crisis del positivismo), como Del Vecchio, Stammler, Tobeñas, Recaséns Fiches.

Mantilla Pineda se vale del pensamiento de las diferentes autoridades del Derecho; de doctrinas como las de Luis Recaséns Siches, Claude du Pasquier, Giorgio del Vecchio, Gustav Radbruch, Felice Battaglia, Miguel Reale y Carlos Cossio, para desplegar su concepción filosófica del Derecho, partiendo de las siguientes premisas:

1. Que la filosofía es un saber subjetivo objetivo.

2. Que la filosofía del Derecho resulta de la aplicación de la filosofía al conocimiento del Derecho.

3. Que el derecho es dialécticamente: norma, conducta y valor.

De acuerdo con el tercer enunciado la filosofía del Derecho se divide en:

3.1. Una ontología jurídica que tiene por objeto la conducta humana intersubjetiva.

3.2. Una lógica jurídica que tiene por objeto la norma de la conducta humana intersubjetiva.

3.3. Una estimativa jurídica que tiene por objeto el valor de la conducta humana intersubjetiva.

Como fácilmente se desprende de lo que antecede, el punto de convergencia de la filosofía del Derecho es la conducta humana intersubjetiva, puesto que sin ella la norma carecería de sentido y el valor no hallaría cumplimiento (Mantilla, 2003).

Antes de desarrollar los diferentes tópicos de la filosofía del derecho -como la noción de filosofía del Derecho, los métodos de la filosofía del Derecho, la ontología jurídica, la lógica jurídica, el Derecho en sentido objetivo, el Derecho en sentido subjetivo, la relación jurídica, la teoría del Estado, la estimativa jurídica, persona y libertad, y los valores jurídicos- advierte que la ontología jurídica, aunque tiene pocos antecedentes (a diferencia de la lógica jurídica que goza de gran resonancia, más particularmente en la filosofía jurídica idealista tanto neo-kantiana como neohegeliana), "está llamada en el porvenir a ocupar el lugar que merece dentro de la filosofía del Derecho" (Mantilla, 2003, p. 16). Se trata de una postura que se haya en concordancia con el núcleo temático del presente trabajo. Igualmente, añade Mantilla Pineda (2003), la estimativa jurídica no es el equivalente exacto de la vieja deontología restringida al problema de la justicia, sino que es una nueva rama de la filosofía del Derecho que examina los valores jurídicos como fuentes materiales mediatas del deber ser jurídico.

Es de resaltar que tanto la primera formulación así como el posterior desarrollo del Tridimensionalismo pertenecen a la obra de autores en su gran mayoría latinoamericanos. Miguel Reale, jurista brasilero y filósofo del Derecho, construyó las bases para su Teoría Tridimensional del Derecho con su tesis Fundamentos de Derecho (1940). Sus obras posteriores, entre las que se destacan Teoria do direito $y$ do Estado (1940), Filosofia do direito (1953), Teoria e pratica do direito (1984), O direito como experiência (1968), y Teoria tridimensional do direito: preliminares históricas e sistêmicas (1968), y otra edición Teoria tridimensional do direito: Una vision integral do direito (1997), sirvieron para desarrollar cada vez más sus postulados iniciales. Es en el último de los libros mencionados es donde sintetiza el significado de su obra. Reale presenta su visión integral del Derecho como un resultado del análisis de las diferentes concepciones tricotómicas de principios del siglo XX en Alemania, Italia, Francia, Estados Unidos, los países Ibéricos de España y Portugal y algunos de Latinoamérica, como Brasil. Realiza dicho análisis tanto desde el aspecto formalista como desde el idealista o realista, exponiendo en qué medida se acercan más o menos 
a la dialecticidad de los tres aspectos fundamentales del Derecho. Desde Fundamentos del Derecho (1940), Reale ya planteaba el tridimensionalismo iusfilosófico como teoría particularmente diferente, tras haber comprendido que las formas de entender el Derecho en los países mencionados, si bien eran tripartitas, no eran integracionistas y que sólo a través de la experiencia jurídica, en un proceso de dialectización, era posible integrar esas tres partes fundamentales del Derecho. En palabras de Reale (1997):

Mi propósito es únicamente mostrar cómo el tridimensionalismo jurídico se vino desarrollando, obedeciendo a intrínsecas necesidades, y cómo el tridimensionalismo específico responde, en el caso particular de la experiencia jurídica, a una comprensión más viva del hombre y del mundo histórico constituido por él. (p. 79).

Reale (1997) propone una postura tridimensional en la cual se da preeminencia al elemento axiológico en tanto que eje de la experiencia jurídica y puente entre la normatividad y el mundo fáctico. Según Reale (1997) "el hombre es el único ente que es $y$ debe ser, en el cual 'ser' y 'deber ser' coinciden, cuyo ser es su deber ser" (p. 90)

Reale (1997) concibe la ontología del Derecho desde el valor en una correlación fácticoaxiológica:

(...) la comprensión de hecho, valor y norma no tanto como elementos, sino como momentos de un proceso, venía a confirmar que, siendo el derecho una dimensión de la vida humana, compartía, o mejor aun, expresaba la dialecticidad del hombre, entendido como 'el único ente que originariamente es y debe ser', o en otras palabras, como 'ente, cuyo ser es su deber ser' (p.103)

Tal correlación entre hecho (lo fáctico) y valor (lo axiológico) es la que da como resultado la norma como integración de orden superior:
(...) considerándose la experiencia jurídica estáticamente en su estructura, o en su funcionalidad o proyección histórica, se verifica que sólo puede ser comprendida en términos de normativismo concreto, consubstanciándose en las reglas de derecho toda la gama de valores, intereses o motivos de que se compone la vida humana, y que el intérprete debe procurar captar, no sólo según las significaciones particulares emergentes de la praxis social, sino también en la unidad sistemática y objetiva del ordenamiento vigente. (Reale, 1997, p.87).

$\mathrm{Y}$ es en estos dos puntos en los que puede basarse una crítica a su postura, en la preeminencia del valor como deber ser sobre el Ser. Al intentar comprender el deber ser del Derecho hay que recordar, primeramente, que la razón de ser del derecho es el ser humano; pues el hacer y el acontecer son inherentes a éste. Lo anterior teniendo en cuenta que la filosofía del Derecho y en ella el tridimensionalismo como postura contemporánea, van encaminadas al reencuentro del Ser como fundamento de toda reflexión filosófica. Todo sistema de valores parte siempre de las circunstancias particulares del individuo. El Ser no es en la medida que un sistema de valores determina su importancia, sino que simplemente es y desde allí se le asigna un valor. Es el ser humano el que entabla una relación con el mundo; sin el ser humano no hay hecho y sin este no hay valor. El acto de apalabrar el mundo es entregarle un valor a través de una acción y sólo el Ser humano tiene esa capacidad. Es decir que el ser humano es el único capaz de crear sistemas de pensamiento y de comportamiento; de interpretar, pero también de reconstruir y volver a nombrar; de significar mundos posibles, además de relacionar no sólo conceptos sino experiencias y valores culturales.

En la medida que no puede hablarse de una verdadera superación del idealismo y del formalismo, Reale, pese al significativo aporte que realiza respecto al avance de la reflexión 
iusfilosófica, no alcanza aún una integración satisfactoria de los tres elementos del Derecho, máxime cuando todavía es evidente en algunas de sus aseveraciones la influencia del positivismo lógico propio de la filosofía analítica:

(...) el tridimensionalismo no nace con el uso de dicho término, pues puede estar subentendido bajo inadecuadas expresiones verbales, aunque el uso conciente del término adecuado sea señal de madurez cognoscitiva. La relación esencial existente entre el pensamiento y el lenguaje es tal que cuanto más nos acercamos al enunciado límpido, más se libera el eidos de un tema de las escorias discursivas que impiden su captación viva y concreta (Reale, 1997, p.79).

Utilizar un léxico específico en la construcción de una teoría no es prueba de que dicha teoría esté bien fundamentada.

En consonancia con la idea que se acaba de subrayar, puede introducirse aquí otro destacado teórico del Derecho: Jesús Ballesteros, catedrático de Filosofía del Derecho en la Universidad de Valencia, quien hace una interpretación del Derecho, contextualizada en el momento actual de la filosofía del Derecho ajustando su discurso a una lectura heiddeggeriana en tanto que habla del Ser como sentido del Derecho (2001). Ballesteros comienza su obra con un tránsito por lo que ha sido la filosofía en Occidente, particularmente desde Descartes, y centrando sus críticas en todo lo que significó la modernidad y el cientificismo; la implantación de una epistemología racionalista y la subsiguiente geometrización de todos los saberes, esto es, el primado del método de la geometría aplicado a todos los campos del conocimiento humano.

Ballesteros (2001) identifica esta problemática con la fisicalización del conocimiento. Frente a la geometría que tenía un método estático, la dinámica del mundo, puesta en boga por Galileo y Newton, facilita que se inaugure el primado de la física como nuevo paradigma epistemológico. El conocimiento, en este sentido, concluye su proceso de modificación. La ciencia suprime la explicación para exaltar la descripción; ya no se buscan las causas sino las leyes; se sustituye el por qué por el cómo. Es desde allí, para Ballesteros, que se opera la desontologización, la ontología muere en manos de la ciencia moderna.

Este primado de la razón calculadora impregna igualmente a la filosofía del Derecho, arrojando como resultado un positivismo jurídico poco consecuente con la realidad existencial del ser humano y permitiendo la aparición de doctrinas arbitrarias como el estatalismo o el absolutismo.

Ballesteros (2001) ve en la modificación de los paradigmas científicos del siglo XX (en cuanto a la física cuántica y la cibernética se refiere) posibilidades para el renacer de la ontología como pilar del conocimiento, debido al papel decisivo que juegan en dichos paradigmas los conceptos de espacialidad, temporalidad, causalidad e indeterminación ligados a lo contingente. Es en esa contingencia y en la pluralidad de lo real que Ballesteros centra su reflexión, recordando los juegos del lenguaje (esto es, imposibilidad de un solo modelo lingüístico) de Wittgenstein, y al mismo tiempo, apela a la búsqueda de lo originario y lo permanente que conduce a la captación de sentido como forma de ser de la ontología al modo heideggeriano.

Habida cuenta de esta postura, señala Ballesteros (2001):

Los temas fundamentales que la filosofía jurídica debe plantearse son el de la estructura ontológica de lo jurídico, de lo que el derecho es como realidad. Para lo cual es necesario superar los reduccionismos modernos, que han encerrado el derecho dentro del estricto campo de la positividad, y de la nacionalidad. Del mismo modo que la fenomenología busca 
el mundo de la vida, más allá de los esquemas modernos del mos geometricus, la filosofía jurídica debe buscar lo jurídico, eliminando los reduccionismos que impiden captar su realidad originaria. Entra aquí de lleno el estudio de la problemática del derecho natural, ya que este no puede ser defendido hoy más que como expresión de las raíces del fenómeno jurídico considerado en su totalidad. (...) la filosofía del derecho debe plantear la cuestión del sentido del derecho en relación con los datos existenciales del ser del hombre, tales como la libertad, la alteridad, la temporalidad, etc., para indagar por el qué de la presencia de lo jurídico en la vida de los hombres. (pp. 85-86)

A partir de aquí desarrolla Ballesteros (2001) los que considera temas básicos de la filosofía del Derecho: el concepto de Derecho fundamentado en el Derecho Natural, la alteridad y la temporalidad como elementos antropológicos vitales y el análisis sociológico, entre otros. Todo ello en aras de la reconstrucción del nexo entre hecho y valor como asunto ontológico, visto desde una postura hermenéutica que se remonta hasta los griegos para entender desde Aristóteles el sentido del Derecho.

La obra de Ballesteros (2001), sin duda, representa un significativo aporte a la fundamentación doctrinal del presente trabajo. Sin embargo, puede a veces echarse de menos una mejor explicación de algunos temas que da por sobreentendidos. Además de esto, su aristotelismo puede ser controvertido desde otras posturas, igualmente heideggerianas como la de Julián Serna, de quien se hablará un poco más adelante.

Con relación a la crítica al proceso de geometrización y fisicalización del conocimiento existe otro texto, Introducción a la Teoría del Derecho (2003) de Gregorio Robles, el que de alguna manera brinda mayor claridad sobre el tema. Gregorio Robles Morchón es catedrático de Filosofía del Derecho en la Universidad de las Islas Baleares y profesor de Derecho de la Unión Europea en la Fundación Mapfre-Estudios en Madrid. Este autor ofrece, en cierta medida, una contrapartida doctrinal a la postura ontologista, pero igualmente ubicable en el marco del Giro Lingüístico, como enseguida se verá.

Robles (2003) expone como elementos esenciales de su obra un tránsito por las que considera las tres etapas del pensamiento jurídico: 1) predominio del iusnaturalismo desde los orígenes de la civilización occidental hasta el s. XVIII; 2) imperio del positivismo jurídico durante el XIX y principios del XX, y 3) crisis epistemológica del positivismo y aparición de posturas superadoras del conflicto Derecho Natural-Derecho Positivo.

De lo anterior se desprende una propuesta de la cual Robles (2003) se hace partícipe, la creación de una Teoría del Derecho:

La Teoría del Derecho quiere dejar de ser una disciplina residual para convertirse en la filosofía jurídica de los juristas. Por eso, su programa de investigación no se puede ver reducido al plan del positivismo, ya que no acepta el estrecho concepto de racionalidad que este postula ni tampoco su diferenciación radical entre ciencia y filosofía. Aunque a algunos les suene a paradoja, el campo de la Teoría del Derecho (...) es mucho más amplio que el de la Filosofía del Derecho surgida en el marco de la mentalidad positivista. Pues para la Teoría del Derecho no puede haber ningún problema teórico que afecte a los juristas y respecto del cual se declare incompetente ${ }^{2}$. (p. 13)

Para Robles, el primer paso que debe darse en el estudio de la Teoría del Derecho y en la generación de un proyecto de investigación propio de ésta es el examen de los diferentes modelos 
epistemológicos; la primacía del problema epistemológico sobre los demás. Por ese camino hace un análisis de lo que ha sido el Derecho Natural y el Derecho Positivo a lo largo de la historia, para llegar al postpositivismo y, desde una hermenéutica filosófica, proponer lo que es para él una verdadera Teoría del Derecho. Ésta comprende cuatro aspectos: un análisis del lenguaje de los juristas; una teoría de los textos jurídicos (en consonancia con lo que ha representado la lingüística textual o Ciencia del Texto, entre cuyos mayores exponentes se encuentra Teun A. van Dijk ${ }^{3}$ ); una teoría hermenéutico-analítica del Derecho y una teoría comunicacional del Derecho.

\section{Al respecto, dice Robles (2003):}

Que la teoría del Derecho, tal como yo la entiendo, es análisis del lenguaje de los juristas quiere decir; en primer lugar, que se propone abandonar las pretensiones ontologistas tanto del iusnaturalismo como del positivismo jurídico, para centrar su interés en comprender las peculiaridades de los diversos tipos de discurso jurídico. El Derecho no es una 'cosa' definible en términos exhaustivos, sino más bien un conjunto de 'discursos' o 'procesos de comunicación' de caracteres peculiares (...) Todos estos actos de lenguaje en que se concreta cada tipo de discurso caben dentro de esta noción: Derecho (p. 19).

Lo que Robles está planteando es, entonces un análisis discursivo-textual-jurídico. Para adoptar su perspectiva epistemológica, apela a un punto de contacto entre la filosofía hermenéutica y la analítica. Ese lugar común es la contingencia del lenguaje. Allí se encontrarían el análisis formal y la búsqueda de sentido para ir construyendo un concepto de Derecho como "un medio de comunicación entre los hombres cuyo objeto es organizar la convivencia y dirigir la conducta. Estamos, pues, ante una Teoría comunicacional del Derecho" (Robles, 2003, p. 25).
Ciertamente, la postura de Robles frente a la ontología, a la que considera como un problema secundario (2003), puede prestarse para una interesantísima e importantísima discusión. Sin embargo, el aporte que ofrece desde la perspectiva rigurosa de las ciencias del lenguaje resulta de gran utilidad.

Con relación a la teoría tridimensional del Derecho, y con un planteamiento ontologista mucho mejor estructurado que los anteriores, se encuentra Naturaleza Tridimensional del Derecho (1999), del peruano Carlos Fernández Sessarego.

Fernández Sessarego concibió, en la segunda mitad de los años cuarenta, conjuntamente con Miguel Reale, la Teoría Tridimensional del Derecho que, admitida internacionalmente, supone una nueva concepción del Derecho en la cual interactúan dinámicamente tres dimensiones: la existencial-sociológica, la axiológica y la normativa. Ninguna, por sí misma, es el Derecho. Sin embargo, no puede faltar ninguna de ellas cuando se alude al objeto de la disciplina jurídica. La aplicación de esta teoría permite la cabal comprensión de toda la institucionalidad jurídica. Esta teoría se formaliza en 1950 en la tesis universitaria que, para obtener el grado de Bachiller en Derecho en la Facultad de Derecho de la Universidad Nacional Mayor de San Marcos, Fernández Sessarego presentó bajo el título Bosquejo para una determinación ontológica del Derecho. Después de permanecer inédita por 37 años la referida tesis se publica bajo el título de El Derecho como libertad (1987), con estudios preliminares de los doctores David Sobrevilla y Domingo García Belaunde. El tema se vuelve a tratar en el libro Derecho y persona (1990). Se han publicado numerosos estudios y comentarios sobre la misma. El autor desarrolló la investigación Iusfilosófica Naturaleza de la persona humana, con la finalidad de fundamentar el Derecho de las Personas precisando, hasta donde ello es posible, las características del ente a ser protegido por el Derecho, teniendo en cuenta que mal se puede tutelar lo que no se conoce o se conoce 
insuficientemente. Se concluye que el ser humano es una unidad psicosomática constituida y sustentada en su Ser libertad. Esta nueva concepción del ser humano, conjuntamente con la Teoría Tridimensional del Derecho, sirve de sustentación a todos los trabajos del autor y se refleja en la normatividad del Código Civil Peruano de 1984, al menos en el Libro Primero sobre Derecho de las Personas. Dicha comprensión del Ser humano queda definida por el autor (1999) al exponer su afinidad doctrinal con Ferrara quien sostiene (como se cita en Fernández Sessarego, 1999) que "el hombre es siempre el punto central del Derecho, y el derecho sólo existe para ordenar las relaciones humanas" (p. 16).

Sobre esta teoría, Fernández Sessarego presenta (1999) una exposición más cercana a un verdadero proceso de dialecticidad integral del Derecho; puesto que no ve al Derecho ni desde su carácter formal (norma), ni desde un aspecto ideal (valor), sino que supera las reducciones abstractas para ubicar al Derecho como algo más cercano a la realidad de la experiencia, es decir, más próximo al ser humano, pues se evidencia en dicha obra un análisis totalizante de la filosofía desde la conducta humana:

(...) sólo el hombre concreto e individual -de carne y hueso como lo calificaría en su momento el apasionado y apasionante Unamuno- es "persona" para el Derecho. Es este ser humano, individual, singular, irrepetible, el único que merece este calificativo. Cualquier otro sujeto de derecho solamente puede adquirir la calidad de persona a través de una ficción, de una construcción conceptual sin asidero en la realidad de la vida, como es el caso del concebido y de la persona jurídica. (Fernández Sessarego, 1999, p. 11).

Se amplían así los horizontes de sentido, rastreando "la huella histórica del concepto de 'persona jurídica' no sólo a nivel del Derecho nacional sino, como está dicho, a través del derecho comparado" (Fernández Sessarego, 1999, p.9).
En este sentido afirma el autor (1999) que:

(...) siendo el derecho primariamente vida humana social, lo regulado por su aparato normativo, bajo la inspiración de los valores, no puede estar desligado de la realidad. (...) El derecho es siempre, y necesariamente, vida humana social. Una exigencia de su propia naturaleza de "ser social", de su dimensión coexistencial. Es así que, como lo hemos repetido a menudo, el ser humano no obstante su unidad ontológica, tiene dos vertientes que se dan simultáneamente. Nos referimos a la individual y a la social. Sin dejar de ser un ente singular, idéntico a sí mismo, el ser humano es, al mismo tiempo, un ente coexistencial. Es decir, que no puede vivir ni realizarse como tal fuera de la sociedad. (p.12)

De esta manera puede verse un importante cambio de postura dentro del marco del Tridimensionalismo, puesto que, mientras Reale se queda en la objetivación del hecho jurídico, en su dimensión normativa, estática, Fernández Sessarego llega al contenido ontológico del Derecho entendido como vida humana, conducta humana dinámica. Sessarego (como se cita en Silva 2006), sostiene que:

No podemos confundir (...) la significación con el objeto y con el hecho. La significación es la norma, el juicio con el que pensamos el objeto del Derecho. Y tal objeto es la libertad que se exterioriza en su relación con otras libertades fenomenalizadas. El objeto del Derecho no es, por tanto, un "conjunto de ideas" fabricadas por el hombre y que "apuntan" a valores. Aquellas ideas, aquellos juicios, aquellos pensamientos mencionan, en tanto que son significaciones, a un objeto que es la conducta humana social (...) Los valores son seres ideales que valen y son objetivos. Pero esta objetividad es una objetividad para la vida humana, están insertados en ella y sólo en ella tienen 
sentido. La conducta es portadora y realizadora de valores. Los realiza y los injerta en las cosas a las que otorga, por tal hecho, un 'sentido'. Los valores por este hecho, son en cierta forma inmanentes a la conducta desde que ella es valorativa. La conducta no 'tiende' hacia valores, no 'apunta' hacia valores, como externo a ella, sino que realiza esos valores permanentemente, como una fatalidad desde que, por ser dato de libertad, consiste en un elegir valorativo, siendo, en sí, estimativa. La conducta es pues substrato de valores (2006, p. 12).

Una visión particular acerca del problema ontológico a lo largo de la historia de la filosofía occidental es presentada por otro autor, Julián Serna Arango, profesor titular de la Universidad Tecnológica de Pereira, quien cuenta con numerosas publicaciones ensayísticas sobre filosofía, entre ellas: Heidegger y la crisis de la modernidad (1992), que a su vez, fue su tesis de grado para optar al título de Doctor en filosofía. Allí postula la crisis del pensamiento occidental y por ende del Ser a partir de una lectura de las obras de Heidegger, a quien ubica en una línea de pensamiento distante de aquella que ha predominado en Occidente a partir de Sócrates, Platón y Aristóteles y que en un largo proceso degeneró en la aparición del positivismo. En contraste con este pensamiento en crisis propio de la modernidad, Serna retoma las investigaciones de Heidegger para mostrar cómo en los orígenes del pensamiento occidental, particularmente en el periodo de los mal llamados presocráticos se intentaba constituir una verdadera filosofía que daba preeminencia a la ontología, al Ser como punto de partida para toda reflexión humana. Sin embargo, en opinión del autor, la tergiversación y mala interpretación del pensamiento filosófico original, el triunfo de las ideas socráticas, platónicas y aristotélicas así como sus posteriores interpretaciones en el medioevo y en el pensamiento cartesiano, kantiano y nietzscheano, produjeron un sistemático olvido del Ser invirtiendo su protagonismo, su papel de fin último de todo esfuerzo humano, al de simple medio para la consecución de otros fines como la riqueza y el poder.

En este sentido Serna hace una lectura de Heidegger en la que se considera la modernidad como última etapa del olvido del Ser y apoteosis del predominio de la técnica, debido a la entronización de las matemáticas como presupuesto de la actividad intelectual (Descartes y Kant); la consideración del hacer como fin en sí mismo (Nietzsche) y la identificación de la actividad científica como última etapa de la supuesta evolución intelectual ascendente de la humanidad (Comte y los herederos del positivismo).

Frente a toda esta gran problemática, Serna intenta una interpretación de las propuestas de Heidegger, tomando como punto de partida el humanismo, el arte, la consideración del lenguaje como eje fundamental del pensamiento, encontrando una posible respuesta en lo que Serna define como poetizar y pensar. De allí que sea necesaria una hermenéutica que entienda que:

Pensar no es una simple intermediación entre el sujeto y el objeto, tendiente a duplicar a este último en el primero, desde un punto de vista formal. El pensar es la avanzada del ser-ahí, dispuesto a conquistar horizontes de sentido, que incrementen (o por lo menos alteren) drásticamente el repertorio de posibilidades disponibles (Serna, 1992, p. 179)

Serna hace una reactualización de sus tesis filosóficas en el libro Teoría del recorte del mundo en occidente (1994) en la que sigue denunciando el evidente recorte de mundo experimentado desde los orígenes de pensamiento occidental hasta la actualidad. Se trata de la reducción del horizonte temático o de sentido, así como de las motivaciones en medio de las cuales se debate la existencia humana. Como cómplices de dicha situación acusa al racionalismo, al cristianismo, al capitalismo y al socialismo marxista, sistemas que convierten al 
ser humano en un medio más que en un fin. Por último, Serna plantea aquí la reconquista de la libertad real, el primado de la solidaridad y las aperturas de sentido (en consonancia con el giro lingüístico) como puntos de partida para la superación de la crisis de la modernidad.

Respecto de la crisis mencionada, conviene tener presente la compilación Comunicación, cultura y globalización (2003), resultado de de las conferencias impartidas por diferentes profesores e investigadores colombianos en el marco de la Cátedra UNESCO de Comunicación 2002, realizada por el Departamento de Comunicación de la Pontificia Universidad Javeriana. En dicha cátedra se fijó el propósito de debatir y analizar los presupuestos conceptuales y las transformaciones propiciadas por la globalización en los ámbitos de la comunicación social, la educación y la cultura desde el contexto de América Latina. Tal propósito ha quedado materializado en las conferencias que desarrollaron los profesores e investigadores invitados y que tratan temas como la transformación que la globalización ha generado en la escuela, los medios de comunicación masiva, la construcción y uso del conocimiento, la aparición de las narrativas mediáticas, el multilingüismo, el cosmopolitismo, la identidad nacional, la política, la economía y la cultura. En dichos análisis de deja claro que la globalización no debe analizarse desde una ideología en particular, puesto que el análisis pierde su imparcialidad y se estarían negando otros puntos de vista, dado que, los problemas que se discuten con respecto a la globalización son multidimensionales.

Finalmente, los capítulos últimos de esta investigación -relativos a algunos temas bioéticos abordados desde una Teoría Tridimesional del Derecho- se basarán en las aportaciones de Jesús Ballesteros, quien cuenta con numerosas publicaciones sobre la ética médica, tema que aborda desde una visión del hombre considerado como el portador del sentido del Derecho. Algunos de los títulos más relevantes son: Crisis
Ecológica: Humanismo vs. Utilitarismo Anglosajón (s.f.); El Individualismo como obstáculo a la universalidad de los derechos humanos (s.f.); El derecho a la vida y el derecho al ambiente (s.f.); La humanidad in Vitro (2002); Medio ambiente y sociedad (1997). En El estatuto del embrión por ejemplo, plantea el embrión, como una cuestión médica desde tres perspectivas: la científica (como individuo de la especie humana), la filosófica (como persona) y la jurídica (como sujeto de derechos). En Exigencias de la dignidad humana en la biojuridica, presenta al hombre como persona jurídica, diferenciándole de las demás especies biológicas, pero no desde los tres diferentes puntos de vista tradicionales (el dualismo, el utilitarismo y la sociobiología) basados en la desacralización e instrumentalización de la realidad, especialmente, del ser humano. Su análisis parte del reconocimiento de la persona como parte integrante de la realidad, pero que descuella como ser trascendente, espiritual, lo cual permite definirlo como sujeto de derechos y deberes en un contexto de dignidad antropológica igual para toda la especie. Asimismo, en Identidad personal y Biojurídica expone la situación de la identidad personal en la postmodernidad decadente, partiendo reiteradamente desde el mismo postulado, el Ser humano y su dignidad como razón de ser del Derecho:

La cuestión fundamental de la biojurídica, que puede ser considerada una parte de la bioética, estriba en determinar quién es titular de derechos y por tanto debe ser tratado como un fin y no puede por tanto ser manipulado a través de la biotecnología, o de la ingeniería genética, salvo en beneficio de sí mismo. A este respecto todas las posiciones coinciden en destacar que el titular de los derechos es siempre quien tiene la condición de persona. Pero las divergencias surgen precisamente en determinar quiénes son personas. 


\section{Conclusiones}

A partir de la revisión de los teóricos ya mencionados, y teniendo en cuenta la meta final del presente proyecto, pueden extraerse las siguientes conclusiones:

1) El pensamiento occidental ha padecido, desde la época clásica, un sistemático recorte en sus horizontes de sentido, caracterizado por el olvido del Ser y la consideración de la riqueza y el poder como fines últimos y no como medios, en un proceso del cual el positivismo es el último y más grande exponente. La filosofía del Derecho, como parte integrante del conocimiento humano, no fue ajena a esta problemática y terminó por sumarse a esta mecánica.

2) Es tarea del Derecho responder a las problemáticas actuales que se vienen generando a partir de la crisis del positivismo como paradigma epistemológico y a la aparición de las nuevas tecnologías. Como consecuencia de esta coyuntura filosófico-sociológica, el Ser es aislado, convirtiéndose en un medio, un ente. Es así como renace la reflexión iusfilosófica, apoyada en un cambio de paradigma: el giro lingüistico, en el que la hermenéutica cobra gran importancia a la hora de enfrentarse a las cuestiones actuales de la ciencia jurídica. La postura heideggeriana, que a partir de una ontología aplicable para el ser humano propone una reflexión existencial, deviene fundamental a la hora de hacer un análisis de la forma de entender el concepto de filosofía (esto es, desde su significación original) y su aplicabilidad en la construcción de una nueva filosofía del Derecho, en la que el ser humano se convierta en el eje fundamental de toda reflexión.

3) Ya en el estricto ámbito de la filosofía jurídica, el tridimensionalismo, como teoría más actual de la filosofía del derecho, ofrece la dialecticidad de las diferentes dimensiones del Derecho. Esa armonización no se logra a través de las visiones formales, ni de las ideales, sino que estas se deben lograr desde la integración de estos elementos en la realidad, contextualizando el Derecho con los problemas sociales e individuales.

4) La pretensión de este proyecto es sentar bases para una reflexión iusfilosófica que rescate la importancia del ser humano como Ser del Derecho. En esa medida, se ha querido revalorar el trabajo de autores como Carlos Fernández Sessarego, quien desde su perspectiva integracionista hace de la ontología un nuevo aporte para la construcción de una Teoría Tridimensional del Derecho mucho mejor fundamentada, y Jesús Ballesteros, quien permanentemente reflexiona sobre los problemas actuales del Derecho en materia de bioética, desde una postura igualmente ontologista.

\section{Notas}

${ }^{1}$ Herbert Marshall McLuhan (1911-1980), escritor canadiense que abordó en su obra el tema de la comunicación. Su teoría, "el medio es el mensaje", se convirtió en el lema de la contracultura de la década de 1960. Nació en Edmonton (Alta), y estudió en las universidades de Manitoba y Cambridge. Dio clases en diversas universidades de Canadá y Estados Unidos.

Sus teorías poco ortodoxas sobre la comunicación tienen su origen en el convencimiento de que los medios electrónicos, en especial la televisión, producen un impacto que supera el material comunicado; sostenía además que la literatura y los libros, en general, serían reemplazados por los medios electrónicos y de la información audiovisual -y eso antes de que existiera el vídeo e Internet-. McLuhan insistió en la necesidad de tomar conciencia de las transformaciones que estos nuevos medios de 
comunicación producirán en la civilización contemporánea. A pesar de que en su opinión los libros no tardarían en quedar obsoletos, escribió varias obras, muchas de ellas en formato ilustrado. Cabe destacar así La galaxia Gutenberg (1962), La comprensión de los medios (1964) y El medio es el masaje (1967).

${ }^{2}$ En cursivas y con negrita en el original.

${ }^{3}$ Teun A. van Dijk, reconocido lingüista holandés, profesor e investigador en Estudios del Discurso y Director del Doctorado en Lingüística de la Universidad de Ámsterdam. Profesor en la Universidad Pompeu Fabra de Barcelona. En sus investigaciones sobre lingüística discursivotextual, enmarcadas en la interdisciplinariedad, van Dijk ha resaltado la importancia del discurso y el texto como correlato indispensable no solo del pensamiento y de la acción sino de la construcción de nuevas estructuras de pensamiento $\mathrm{y}$, por ende, de nuevos comportamientos sociales.

\section{Referencias}

Alba, G.; Arias, J., Cruz, H.; Ferrari, C., Forero, M.; Gutiérrez, E., Marín, L. Fernando, Moreno, M., Ortiz, R., Rincón, O., Santos, D., Sierra, F., Sierra, L. I., y Valencia, D. (2003). Comunicación, cultura y globalización. Bogotá, UNESCO; versión de la cátedra de Comunicación Social de la Pontificia Universidad Javeriana.

Ballesteros, J. (2001). Sobre el sentido del Derecho. Madrid, Tecnos.

Ballesteros, J. (s.f.). Crisis Ecológica: Humanismo vs. Utilitarismo Anglosajón. Recobrado el 4 de agosto de 2007 desde http://www.ulia.org/ficv/document.htm.

Ballesteros, J. (s.f.). El Individualismo como obstáculo a la universalidad de los derechos humanos. Recobrado el 4 de agosto de 2007 desde http://www.ulia.org/ficv/document. htm.
Ballesteros, J. (s.f.). El derecho a la vida y el derecho al ambiente. Recobrado el 4 de agosto de 2007 desde http://www.ulia.org/ ficv/document.htm.

Ballesteros, J. (s.f.). Exigencias de la dignidad humana en Biojurídica. Recobrado el 4 de agosto de 2007 desde http://www.ulia.org/ ficv/document.htm.

Ballesteros, J. (s.f.). Identidad personal y Biojurídica. Recobrado el 4 de agosto de 2007 desde http://www.ulia.org/ficv/ document.htm.

Ballesteros, J. (s.f.) El estatuto del Embrión. Recobrado el 4 de agosto de 2007 desde http://www.ulia.org/ficv/document.htm.

Ballesteros J. y Pérez A. (1997). Medio ambiente y sociedad, Madrid, Trotta.

Ballesteros J. (Coordinador) Aparisi Miralles, A. (2002). La humanidad in Vitro. Granada, Comares.

Ballesteros J y Fernández E. (s.f.). Biotecnología y Posthumanismo. La Cátedra Garrigues de Derecho Global de la Universidad de Navarra, The Global Law Collection, Thomson Aranzadi.

Bodenheimer, E. (1997). Teoría del Derecho. Bogotá, Fondo de Cultura Económica.

Coaguila Valdivia J. F. (s.f.). La interdisciplinariedad del Derecho. Revista Telemática de Derecho y Filosofía. 1997 - 2007.

Coaguila Valdivia J. F. (s.f.). La postmodernidad light. Crítica sobre las nociones de Postmodernidad en el discurso jurídico contemporáneo. Revista Telemática de Derecho y Filosofía. 1997 - 2007.

Del Vecchio, G. (1936. a.). Filosofía del Derecho. Tomo II. Barcelona, Bosch. 
Del Vecchio, G. (1936. b.) Historia de la Filosofía del Derecho. Barcelona, Bosch.

Fernández Sessarego, C. (1962). La noción jurídica de persona, Universidad Nacional Mayor de San Marcos, Lima.

Fernández Sessarego, C. (1973). Bosquejo para una determinación ontológica del Derecho, de la cual se publicó un fragmento bajo el título de "Pluralidad de elementos que integran el derecho" en la revista "Derecho" $\mathrm{N}^{\circ} 31$, editada por la Pontificia Universidad Católica de Lima.

Fernández Sessarego, C. (1994.a.). Derecho de las personas. Lima, Studium.

Fernández Sessarego, C. (1994.b.). El derecho como libertad. Universidad de Lima, Lima, segunda edición.

Fernández Sessarego, C. (octubre - diciembre 1995). Visión tridimensional de la persona jurídica, publicado en los Anales de la Academia Nacional de Derecho y Ciencias Sociales de Buenos Aires y en la "Revista Jurídica del Perú", Año XLV, No 4, pág. 17 y ss.

Fernández Sessarego, C. (1999) Naturaleza tridimensional de la persona jurídica. El articulo ha sido publicado en "Derecho PUC", $\mathrm{n}^{\mathrm{o}}$ 52, Revista de la Facultad de Derecho de la Pontificia Universidad Católica del Perú, Lima, abril-diciembre de 1999.

Fernández Sessarego, C. (2001) La Antijuricidad como Problema, El articulo originalmente ha sido publicado en la revista "Lumen", de la Facultad de Derecho de la Universidad Femenina del Sagrado Corazón, Año 1, $\mathrm{N}^{\circ}$ 1, Lima, 2000 y en el libro de autores varios "Obligaciones y contratos en el tercer milenio". Homenaje a Roberto López Cabana, Buenos Aires, Abeledo-Perrot.

Fernández Sessarego, C. (2002). Qué es ser persona para el Derecho (2002). El articulo ha sido publicado en el volumen "Derecho Privado", Libro en Homenaje a Alberto J. Bueres, Editorial Hammurabi, Buenos Aires, 2001 y en "Derecho PUC", N 53, Universidad Católica.

Friedrich, C. J. (1997). La Filosofía del Derecho. México, Fondo de Cultura Económica.

Graves, R. (2002). Introducción a los Mitos Griegos en Los Mitos Griegos. Tomo I. Traducción de Esther Gómez Parro. Madrid, Alianza.

Grün, E. (1997). El Derecho posmoderno: un sistema lejos del equilibrio. El presente trabajo, remitido a la RTFD por el autor, fue presentado como ponencia en el XVIII Congreso Mundial de la Asociacion Internacional de Filosofía del Derecho y de Filosofía Social. Buenos Aires (Argentina), agosto de 1997.

Grün, E. (s.f.). La crisis del sistema jurídicopolítico argentino desde un enfoque sistémico y cibernético. Revista Telemática de Derecho y Filosofía. 1997 - 2007.

Heidegger, M. (1977). Introducción a la Metafísica. Buenos Aires, Nova.

Heródoto. (1975). Los Nueve Libros de la Historia. Los Clásicos. USA, W. M. Jackson INC.

Jongitud Zamora, J. (s.f.). Teorías éticas contemporáneas. Revista Telemática de Derecho y Filosofía. 1997 - 2007.

Krebs, R. (1992). La monarquía absoluta en Europa: el desarrollo del Estado moderno en los siglos XVI, XVII y XVIII. Santiago de Chile, Editorial Universitaria, $3^{\mathrm{a}} \mathrm{ed}$.

Le Goff, J. (1983). Tiempo, trabajo y cultura en el occidente medieval. Madrid, Taurus.

Lublinskaya, A. D. (1983). La crisis del siglo XVII y la sociedad del absolutismo. Barcelona, Crítica. 
Mantilla Pineda, B. (2003). Filosofía del Derecho. Bogotá, Temis.

Mcluhan, H. M. (1967). El medio es el masaje. Traducción de León Mirlas. Barcelona, Paidós.

Mcluhan, H. M. (1969). La galaxia Gutenberg. Traducción por Juan Novella. Madrid, Aguilar.

Mcluhan, H. M. (1996). La comprensión de los medios. Traducción de Patrick Ducher. Barcelona, Paidós.

Olmo Bau C. S. (s.f.). Ética, Derecho y Politica en la Filosofía de la Historia. Hegel y Marx. Revista Telemática de Derecho y Filosofía. 1997-2007.

Pla Vargas, L. (2006). El Mundo Apalabrado. En Astrolabio. Revista internacional de filosofía. Año 2006. Núm. 2.

Poratti, A. E., L. C; Santa Cruz De Prunes, M. I. y Cordero, N. L. (1997). Los filósofos presocráticos. Tomo III. Madrid, Gredos.

Reale, M. (1976.a.). Fundamentos del Derecho. Buenos Aires, Desalma.

Reale, M. (1976.b.). Filosofía del Derecho. Buenos Aires, Desalma.

Reale, M. (1984). Teoría y práctica del Derecho. Sao Paulo, Saraiva.

Reale, M. (1992). Del Derecho como experiencia: introducción a la epistemología jurídica. $2^{\mathrm{a}}$ ed., Sao Paulo, Saraiva.

Reale, M. (1993). Invariantes axiológicas. Ius et Veritas 5 (10): 317-322, julio 1995; Introducción al derecho. $10^{\mathrm{a}}$ ed., Madrid, Pirámide.

Reale, M. (diciembre 1996). El término "tridimensional" y su contenido. Derecho (50): 5-9.
Reale, M. (1997). Teoría Tridimensional del Derecho: Una visión Integral del Derecho. Traducción e introducción de Ángeles Mateos. Madrid, Tecnos.

Recaséns Siches, L. (1963). Panorama del pensamiento jurídico en el siglo $X X$. México, Porrúa.

Robles, G. (2003). Introducción a la Teoría del Derecho. 6ta Edición. Barcelona, RandomHouse Mondadori.

Serna Arango, J. (1992). Heidegger y la Crisis de la Modernidad. Corporación Biblioteca Pública: Colección de Escritores Pereiranos. Pereira.

Serna Arango, J. (1994). Teoría del recorte de mundo en occidente Corporación Biblioteca Pública: Colección de Escritores Pereiranos. Pereira.

Silva Cueva; J. (2006). Artículo de Revista: Visión tridimensional del Derecho. Por la Revista Telemática de filosofía del Derecho.

Truyol Y Serra, A. Historia de la filosofía del derecho y del Estado. 2 vols. Madrid: Alianza Editorial, S.A., 13 ${ }^{a}$ ed., 1998.

Van Dijk, T. A. (1980 a) Texto y Contexto. Semántica y Pragmática del Discurso. Madrid, Cátedra.

Van Dijk, T. A. (1980 b) Estructuras y funciones del Discurso. México, Siglo XXI.

Van Dijk, T. A. (1983) La ciencia del Texto. Madrid, Paidós.

Van Dijk, T. A. (febrero de 2004). Artículo de revista: Discurso y dominación. Bogotá: Grandes conferencias en la Facultad de Ciencias Humanas. Universidad Nacional de Colombia. $\mathrm{N}^{\mathrm{o}} 4$. 